RESEARCH

Turkish Journal of Geriatrics

DOI: $10.31086 /$ tjgeri.2021.254

2021; 24(4): 567-577

• Şerife GÖKBULUT BEKTAŞ ${ }^{1}$

- Seval IZDEŞ²

CORRESPONDANCE

${ }^{1}$ Şerife GÖKBULUT BEKTAŞ

Ankara City Hospital, Intensive Care Unit, Ankara, Turkey

\section{Phone: +905052622172}

e-mail: serifegbektas@gmail.com

Received: Aug 17, 2021

Accepted: Kas 22, 2021

${ }^{1}$ Ankara City Hospital, Intensive Care Unit, Ankara, Turkey

${ }^{2}$ Ankara Ylldrım Beyazt Üniversity, Intensive Care Unit, Ankara, Turkey

\section{THE EFFECT OF THE VITAMIN D LEVEL ON THE CLINICAL, LABORATORY, AND OUTCOME IN PATIENTS OVER 65 YEARS OF AGE WITH COVID-19: COMPREHENSIVE TERTIARY CENTER EXPERIENCE}

\section{Abstract}

Introduction: This study aimed to examine the relationship between vitamin $D$ levels and the disease course, laboratory results, and clinical outcomes in patients aged $>65$ years with coronavirus disease 2019 (COVID-19).

Methods: The laboratory and clinical results of patients aged $>65$ years who were admitted to a tertiary intensive care unit due to COVID-19 between April 2020 and May 2021 were retrospectively examined.

Results: A total of 299 patients aged >65 years (median: 76 years [interquartile range: 70-83]) diagnosed with COVID-19 were admitted in the ICU. The regression analysis performed between vitamin $D$ level $\geq 30 \mathrm{ng} / \mathrm{mL}$ and $<30 \mathrm{ng} / \mathrm{mL}$ and the inflammatory markers revealed the significant correlation of vitamin $D<30 \mathrm{ng} / \mathrm{mL}$ with a low lymphocyte count and fibrinogen level. When the relationship between mortality, inflammatory markers, and clinical parameters was examined, lymphocyte count, D-dimer level, fibrinogen level, chest tomography stage 3 , and vitamin D deficiency were also effective factors for predicting mortality. In COVID-19 patients, the vitamin D cut-off value for mortality was found to be $18.5 \mathrm{ng} / \mathrm{mL}$.

Conclusion: We observed a high rate of patients with low vitamin D levels in patients aged $>65$ years who were admitted to the intensive care unit due to COVID-19. The rates of inflammation and mortality were higher in patients with vitamin $\mathrm{D}$ deficiency.

Keywords: Vitamin D; COVID-19; Aged; Mortality; Intensive Care Unit; Inflammation. 


\section{INTRODUCTION}

The coronavirus disease (COViD-19), caused by the severe acute respiratory syndrome coronavirus 2, has spread worldwide, resulting in millions of cases since December 2019 (1). Little is known about the protective factors against this deadly infection (2). Moreover, the mortality rate can differ greatly, even between neighboring countries, and many factors could have a role in this disparity, including general health, accessibility and quality of healthcare, socioeconomic status, and the percentage of elderly people in a population (2). One overlooked factor that could influence the outcome of COVID-19 is the population's relative vitamin D status, especially in elderly people (2). Because our scientists advised staying at home as much as possible, our government compelled the elderly people to stay at home over the next 6 months. Naturally, vitamin D levels were affected by this decision. As such, we aimed to determine if there is a relationship between basal vitamin D levels and elderly mortality and whether the decision to limit the movement of only the elderly was correct.

In a comprehensive study conducted in 40 countries, vitamin $D$ deficiency was present in more than $50 \%$ of the participants, especially in the elderly (3). Previous studies have shown that individuals with vitamin $D$ deficiency are more likely to be infected with COVID-19 (2). In addition, it has been shown that there is a relationship between the incidence and severity of some viral infections, such as influen$z a$, and the immunomodulatory effect of vitamin $D$ deficiency (4). In this study, we aimed to comprehensively investigate how vitamin D deficiency affected the course, severity, and outcomes of COVID-19 in patients aged $>65$ years in a tertiary intensive care unit.

\section{METHODS}

\section{Study population}

This study was conducted through the retrospective screening of 293 COVID-19 patients hospi- talized between April 2020 and May 2021 in the tertiary care unit of the Ankara City Hospital. Laboratory-confirmed COVID-19 patients (with real-time reverse transcription-polymerase reaction) aged $>65$ years were admitted to the ICU. This study was approved by the local ethics committee. No data were available regarding the prior use of vitamin D or other supplements.

\section{Data collection}

Patient demographics, comorbidities, APACHE II scores, laboratory tests (complete blood count, biochemical and coagulation tests, C-reactive protein $[\mathrm{CRP}]$, procalcitonin, and interleukin-6 [IL-6] levels), and outcomes were recorded. The serum 25-hydroxyvitamin $\mathrm{D}_{3} \quad(25(\mathrm{OH}) \mathrm{D})$ concentrations were measured using a chemiluminescent assay (Elecsys 2010 analyzer, Roche Diagnostics, Mannheim, Germany) and categorized into four groups: sufficient ( $\geq 30 \mathrm{ng} / \mathrm{mL})$, insufficient $(<30-20 \mathrm{ng} / \mathrm{mL}$ ), and deficient $(<20 \mathrm{ng} / \mathrm{mL})$.

\section{Chest computerized tomography (CT)}

The patients also underwent chest $X$-rays and chest CT scans. Initial chest CT was performed in all patients between the 1st and the 7th day after hospitalization. ARDS was diagnosed using the Berlin standards. In addition, the CT phases of our patients were assigned according to the previously determined temporal radiologic COVID-19 disease: stage 1, ground-glass opacities (early stage); stage 2 , crazy paving pattern (progressive stage); and stage 3, consolidation (peak stage).

\section{Confounding comorbidities}

Comorbidities (diabetes, hypertension, coronary artery disease, chronic renal failure, asthma, and chronic obstructive pulmonary disease) were obtained separately from previous medical records and the anamnesis of the patients. Those with malignancy were excluded from the study because of 
the tumors' effects on vitamin D metabolism and their strong contribution to mortality.

\section{Statistical Analysis}

Statistical analyses were performed using the SPSS software (version 15, SSPS Inc. Chicago, USA) for Windows. All variables were checked for normal distributions. Variables are reported as means and standard deviations or as medians and interquartile range (IQR), when appropriate. Continuous variables were compared using the Student's t-test or the Mann-Whitney $U$ test. The chi-square test was used to test the proportions. Statistical significance was set at $p \leq 0.05$. The association between mortality and clinical and inflammatory marker variables was assessed using binary logistic regression analysis. Receiver operating characteristic curves were used to determine the optimal vitamin D cutoff points for mortality.

\section{RESULTS}

\section{Study population}

A total of 299 patients aged $>65$ years with a diagnosis of COVID-19 were followed up in the ICU. Six patients with malignancy were excluded from the study, and the remaining 293 patients were included in the analysis, including 129 (44\%) women and 164 (56\%) men. The median age of the patients was 76 (IQR: 70-83) years. The median overall vitamin D level was $19 \mathrm{ng} / \mathrm{mL}$ (IQR: 12-26). Vitamin D deficiency was present in 150 patients (51.2\%), with 96 patients (32.8\%) in the insufficient group and 47 (16\%) in the sufficient group. The length of stay in the ICU in the survived patients was 16 days (IQR: 8.5-23) in the deficient group, 11 days (IQR: 6-18.5) in the insufficient group, and 9 days (IQR: $5-16$ ) in the sufficient group $(p=0.04)$. A total of $171(58.4 \%)$ and 122 patients (41.6\%) were treated in the winter and summer months, respectively. The median APACHE II score was 18 (IQR: 12-26) in the deficient group, 22 (IQR: 12-28) in the insufficient group, and 19 (IQR: $13-26)$ in the sufficient group $(p=0.3)$ (Table 1).

Table 1. The Clinical Characteristics of Patients

\begin{tabular}{|l|c|c|c|c|c|}
\hline & Overall & Deficiency & Insufficient & Sufficent & $\mathbf{p}$ \\
\hline Numbers (\%) & $293(100)$ & $150(51.1)$ & $96(32.7)$ & $47(16)$ & - \\
\hline Vitamin D Levels, Median,(IQR) & $19(12-26)$ & $12(9-15.1)$ & $24(21-26.7)$ & $41(34-58)$ & - \\
\hline Sex & & & & & \\
Male (\%) & $164(56)$ & $89(59.3)$ & $50(52.1)$ & $25(53.2)$ & 0.3 \\
Female (\%) & $129(44)$ & $61(40.7)$ & $46(47.9)$ & $22(46.8)$ & \\
\hline Age, Median,(IOR), y & $76(70-83)$ & $76(70-82)$ & $78(71-84)$ & $75(69-82)$ & 0.4 \\
\hline APACHE, (IQR) & $19(12-32)$ & $18(12-26)$ & $22(12-28)$ & $19(13-26)$ & 0.3 \\
\hline Season (\%) & & & & & \\
Winter & $171(58.4)$ & $87(58)$ & $55(57.3)$ & $29(61.7)$ & 0.8 \\
Summer & $122(41.6)$ & $63(42)$ & $41(42.7)$ & $18(38.3)$ & \\
\hline Comorbidity (\%) & & & & & \\
Diabetes & $115(39.2)$ & $59(39.3)$ & $38(39.6)$ & $18(38.3)$ & 0.9 \\
Hypertension & $227(77.5)$ & $114(76)$ & $78(81.2)$ & $35(74.5)$ & 0.8 \\
Coronary Artery Disease & $82(28)$ & $39(26)$ & $31(32.3)$ & $12(25.5)$ & 0.7 \\
Cancer Chronic Kidney Disease & $16(5.5)$ & $8(5.3)$ & $2(2.1)$ & $6(12.8)$ & 0.2 \\
Cerebrovascular Diseases & $33(11.3)$ & $13(\% 8.7)$ & $17(17.7)$ & $3(6.4)$ & 0.6 \\
Asthma & $23(7.8)$ & $11(7.3)$ & $7(7.3)$ & $5(\% 10.6)$ & 0.5 \\
Chronic obstructive pulmonary disease & $19(6.5)$ & $13(8.7)$ & $5(5.2)$ & $1(2.1)$ & 0.09 \\
\hline
\end{tabular}

IQR: Interquartile Range 


\section{Vitamin $D$ and confounding factors}

Of the 293 patients, 115 (39.2\%) had diabetes, $227(77.5 \%)$ had hypertension, 82 (28\%) had coronary artery disease, 33 (11.3\%) had chronic kidney disease, 23 (7.8\%) had cerebrovascular events, 19 (6.5\%) had asthma, and 36 (12.6\%) had chronic obstructive pulmonary disease. When the groups with vitamin D deficiency, vitamin D insufficiency, and vitamin $D$ sufficiency were compared in terms of confounding factors, no significant difference was found ( $p>0.05$, Table 1). When the relationship between mortality and confounding factors and other clinical factors was examined by binary logistic regression analysis, it was observed that confounding factors had no effect on mortality (Table 3 ).

\section{Vitamin D and inflammation}

The vitamin $D$ and lymphocyte counts were 520 (IQR: $310-730) 10^{3} \mu \mathrm{L}$ in the deficient group, 590 (IQR: $370-890) 10^{3} \mu \mathrm{L}$ in the insufficient group, and 790 (IQR: 400-1280) $10^{3} \mu \mathrm{L}$ in the sufficient group. The association between the 25(OH)D groups and fibrinogen level was detected to be 5.16 (IQR: 3.88-6.86) $\mathrm{g} / \mathrm{L}$ in the deficient group, 5.04 (IQR: 3.92-6.39) $\mathrm{g} / \mathrm{L}$ in the insufficient group, and 4.55 (IQR: 3.88-5.12) $\mathrm{g} / \mathrm{L}$ in the sufficient group. There was a significant correlation between the vitamin $D$ level and both the lymphocyte count and fibrinogen level ( $p=0.02, p=0.001$, respectively) (Figure 1). When the relationship between the D-dimer, CRP, troponin $\mathrm{T}$, and vitamin $\mathrm{D}$ levels was examined, we found 2.03 (IQR: 0.9-4.08) mg/L, 124 (IQR: 55-184) $\mathrm{mg} / \mathrm{L}$, and 42.8 (IQR: $11-160.5) \mathrm{ng} / \mathrm{mL}$ in the deficient group; 1.85 (IQR: 0.92-4.1) mg/L, 112 (IQR: 50181) $\mathrm{mg} / \mathrm{L}$, and 42 (IQR: $17-140) \mathrm{ng} / \mathrm{mL}$ in the insufficient group; and 1.5 (IQR: 0.9-3.8) mg/L, 79 (26-149) $\mathrm{mg} / \mathrm{L}$, and $25(11-118) \mathrm{ng} / \mathrm{mL}$ in the sufficient group. No relationship was found between any of the three inflammatory markers and vitamin $D(p=0.751, p=$ 0.19 , and $p=0.555$, respectively). As for the association of the vitamin D groups with the IL-6 and ferritin levels, we observed 47 (IQR: 23.3-123) pg/mL and
556 (IQR: 378-1164) $\mathrm{mg} / \mathrm{L}$ in the deficient group, 44.1 (IQR: 16-111) pg/mL and 532 (IQR: 321-1060) $\mathrm{mg} / \mathrm{L}$ in the insufficient group, and 32 (IQR: 13-69.3) $\mathrm{pg} / \mathrm{mL}$ and 372 (IQR: 176-601) mg/L in the sufficient group. A significant relationship was observed between vitamin $D$ and both IL-6 and ferritin levels ( $p$ $=0.016$ and $p=0.002$, respectively) (Table 2).

In the regression analysis including vitamin $D$ levels $\geq 30 \mathrm{ng} / \mathrm{mL}$ and $<30 \mathrm{ng} / \mathrm{mL}$ and inflammatory markers, the following results were found: lymphocyte count, odds ratio (OR): 1 (95\% Cl: 0.9-1 \& $p=.0 .033$ ); CRP level, OR: 0.99 (95\%Cl: 0.99-1\& $\mathrm{p}=.0 .44)$; fibrinogen level, OR: 1 (95\% Cl: 0.99-1 \& $\mathrm{p}=.0 .016)$ ) D-dimer level, OR: 0.97 (95\% Cl: 0.91-1.02 $\& p=.0 .3)$; IL-6 level, OR: 0.99 (95\%Cl: 0.98-1.02\& $\mathrm{p}=.0 .088)$; troponin T level, OR: $1(95 \% \mathrm{Cl}: 1-1 \&$ $\mathrm{p}=.0 .43)$; and ferritin level, OR: 0.77 (95\%Cl: 0.62$0.95 \& p=.0 .08)$. A significant correlation was found among lymphocyte count, fibrinogen level, and vitamin D level $<30 \mathrm{ng} / \mathrm{ml}$ (Table 2).

Figure 1. Box and whisker graph showing the D-dimer levels, fibrinogen levels, and lymphocyte counts in the vitamin $D$ groups. The relationship between the vitamin D groups and inflammation was significant between fibrinogen levels $(p=0.001)$ and lymphocyte count $(p=0.02)$ but not between D-dimer levels $(p=0.751)$. (D-dimer levels $=\mathrm{mg} / \mathrm{L}$, fibrinogen levels $=\mathrm{g} / \mathrm{L}$, lymphocyte count $=10^{3} \mu \mathrm{L}$ )

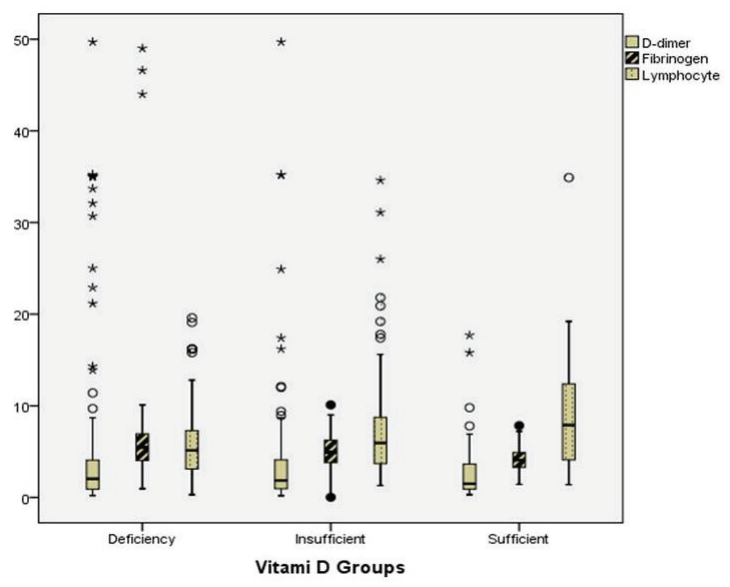


Table 2. Comparison of the laboratory findings and evaluations of Lung Results

\begin{tabular}{|c|c|c|c|c|}
\hline & Deficiency & Insufficient & Sufficent & p \\
\hline Lymphocyte, Median (IQR) $10^{3} \mu \mathrm{L}$ & $520(310-730)$ & $590(370-890)$ & $790(400-1280)$ & 0.02 \\
\hline CRP, Median (IQR) mg/L & $124(55-184)$ & $112(50-181)$ & 79(26-149) & 0.19 \\
\hline Fibrinogen, Median (IQR) g/L & $5.16(3.88-6.86)$ & $5.04(3.92-6.39)$ & $4.55(3.88-5.12)$ & 0.001 \\
\hline D-dimer, Median (IQR) mg/L & 2.03(0.9-4.08) & $1.85(0.92-4.1)$ & $1.5(0.9-3.8)$ & 0.751 \\
\hline IL-6, Median (IOR) pg/mL & $47(23.3-123)$ & $44.1(16-111)$ & $32(13-69.3)$ & 0.016 \\
\hline Troponin T, Median (IQR) ng/mL & $42.8(11-160.5)$ & $42(17-140)$ & $25(11-118)$ & 0.555 \\
\hline \multirow[t]{2}{*}{ Ferritin, Median (IQR) mg/L } & $556(378-1164)$ & $532(321-1060)$ & $372(176-601)$ & 0.002 \\
\hline & \multicolumn{3}{|c|}{$<30 \mathrm{ng} / \mathrm{ml}$} & $p$ \\
\hline Lymphocyte, OR (95\%Cl) & \multicolumn{3}{|c|}{$1(0.9-1)$} & 0,033 \\
\hline CRP, OR $(95 \% \mathrm{Cl})$ & \multicolumn{3}{|c|}{ 0,99(0.99-1) } & 0.44 \\
\hline Fibrinogen, OR (95\%Cl) & \multicolumn{3}{|c|}{$1(0.99-1)$} & 0.016 \\
\hline D-dimer, OR $(95 \% \mathrm{Cl})$ & \multicolumn{3}{|c|}{$0.970 .91-1.02)$} & 0.3 \\
\hline IL-6, OR (95\%Cl) & \multicolumn{3}{|c|}{$0.99(0.98-1)$} & 0.088 \\
\hline Troponin T, OR (95\%Cl) & \multicolumn{3}{|c|}{$1(1-1)$} & 0.43 \\
\hline \multirow[t]{2}{*}{ Ferritin, OR $(95 \% \mathrm{Cl})$} & \multicolumn{3}{|c|}{$0.77(0.62-0.95)$} & 0.08 \\
\hline & Deficiency & Insufficient & Sufficent & $p$ \\
\hline ARDS (\%) & $101(67.3)$ & $62(64.6)$ & $22(46.8)$ & $0.02^{\star}$ \\
\hline $\begin{array}{l}\text { Chest Tomography Stage } \\
\text { Stage } 1(\%) \\
\text { Stage } 2(\%) \\
\text { Stage } 3(\%)\end{array}$ & $\begin{array}{c}30(20) \\
53(35.3) \\
67(44.7)\end{array}$ & $\begin{array}{l}26(27.1) \\
34(35.4) \\
36(37.5)\end{array}$ & $\begin{array}{l}19(40.4) \\
17(36.2) \\
11(23.4)\end{array}$ & $0.002^{\star}$ \\
\hline & \multicolumn{2}{|c|}{$<30 \mathrm{ng} / \mathrm{ml}$} & $\geq 30 \mathrm{ng} / \mathrm{ml}$ & $p$ \\
\hline $\begin{array}{l}\text { ARDS, OR }(95 \% \mathrm{Cl}) \\
\text { Negative } \\
\text { Positive }\end{array}$ & & $\begin{array}{c}\text { Reference } \\
0.49(0.25-0.97)\end{array}$ & & 0.043 \\
\hline $\begin{array}{l}\text { Chest Tomography Stage, OR }(95 \% \mathrm{Cl}) \\
\text { Stage } 1 \\
\text { Stage } 2 \\
\text { Stage } 3\end{array}$ & & $\begin{array}{c}\text { Reference } \\
0.5(0.23-1.07) \\
0.37(0.16-0.85)\end{array}$ & & $\begin{array}{l}0.07 \\
0.02\end{array}$ \\
\hline
\end{tabular}

IQR: Interquartile Range, OR: Odds Ratio, Cl: Confidence Interval 


\section{Vitamin $D$ and lung outcomes}

It was found that $67.3 \%$ of the patients with ARDS (101 patients) were in the deficient category, 64.6\% (62 patients) were in the insufficient category, and $46.8 \%$ (22 patients) were in the sufficient category. Patients with sufficient vitamin $D$ levels had significantly lower cases of ARDS ( $p=0.02)$. As for the relation of the patients' $\mathrm{CT}$ findings with their vitamin D group, there were 30 patients (20\%) in Stage 1, 53 patients in Stage 2 (35.3\%), and 67 patients in Stage $3(44.7 \%)$ in the deficient group; 26 patients (27.1\%) in Stage 1, 34 patients (35.4\%) in Stage 2, and 36 patients (37.5\%) in Stage 3 for the insufficient group; and 19 patients in Stage 1 (40.4\%), 17 patients in Stage 2 (36.2\%), and 11 patients in Stage 3 (23.4\%) in the sufficient group. The difference between the vitamin D groups and $C T$ results was significant $(p=0.002$; Table 2). In the logistic regression analysis between vitamin $D$ levels and ARDS, the OR was $0.49(0.25-0.97)(P=0.043)$ in the patients with ARDS and vitamin D level $<30 \mathrm{ng} / \mathrm{mL}$. In addition, CT Stage 2 (OR 0.5 [0.23-1.07], $P=0.07$ ) and Stage 3 (OR 0.37 [0.16-0.85], $\mathrm{P}=0.02$ ) were found in patients with a vitamin $D$ level $<30 \mathrm{ng} / \mathrm{mL}$.

\section{Mortality}

In the patients who expired, the lymphocyte count was 510 (310-730) $10^{3} \mu \mathrm{L}$, while it was 650 (3951010) $10^{3} \mu \mathrm{L}$ in the survivors $(p=0.001)$. Additionally, in the patients with mortality, the CRP, fibrinogen, and D-dimer levels were 117 (50.2-184) $\mathrm{mg} / \mathrm{L}, 7.1$ (3.68-6.94) g/L, 3.35 (1.6-6.6) mg/L, 105 (37.5-165) $\mathrm{mg} / \mathrm{L}$, while these were $4.08(2.31-4.85) \mathrm{g} / \mathrm{L}, 1$ (0.71.7) $\mathrm{mg} / \mathrm{L}$ in the survivors ( $p=0.001$ for each). The IL6 , troponin $\mathrm{T}$, and ferritin levels were 44 (17.7-109.7) $\mathrm{pg} / \mathrm{mL}$, 52 (9.6-134), 545 (197-1099) ng/mL, respectively, in the patients who expired, whereas these were 40.3 (16-87.8) pg/mL, 30 (14.7-147) and 507 $(271-1058) \mathrm{ng} / \mathrm{mL}$ in the survivors. These differences were not statistically significant $(p>0.05)$. Binary logistic regression analysis was performed on all inflammatory markers between patients with mortal- ity and survived. This analysis showed that the lymphocyte count (OR: 0.9 [0.99-1], $p=0,025]$, D-dimer level [OR: 2, [1.59-2.53], $p=0.001)$, and fibrinogen level (OR: 2.3 [1.71-3.01], $p=0.001$ ) were all related to mortality (Table 3). While there was a positive correlation between mortality and the fibrinogen and D-dimer levels, there was a negative correlation with lymphocyte count.

Binary logistic regression analysis was performed on all clinical parameters between patients with mortality and survived, and it was found that positive ARDS (OR: 0.43 [0.23-0.81], $p=0.01$ ), CT Stage 2 (OR: 0.22 [0.11-0.44], $p=0.035), C T$ Stage 3 (2.79 [1.39-5.61], $p=0.001)$, vitamin $D$ insufficiency (OR: 2.5 [1.06-5.86], $\mathrm{p}=0.035)$, and vitamin $\mathrm{D}$ deficiency (OR: 3.86 [1.72-8.65], $p=0.001$ ) were associated with mortality (Table 3).

Using the receiver operating characteristic curve, a cutoff point of $18.5 \mathrm{ng} / \mathrm{mL}$ was used for vitamin $D$ deficiency, based on mortality (the surface area under the curve of $61.6 \%[\mathrm{Cl} 95 \%=54.8-$ $68.4 \%, p=0.001$ ) (Figure 2).

Figure 2. Receiver operating characteristic curve showing $25(\mathrm{OH}) \mathrm{D}$ level $=18.5 \mathrm{ng} / \mathrm{mL}$ as the cutoff point of vitamin $D$ deficiency for mortality [the surface area under the curve of $61.6 \%[\mathrm{Cl} 95 \%$ $=54.8-68.4 \%$, $(p=0.001)]$.

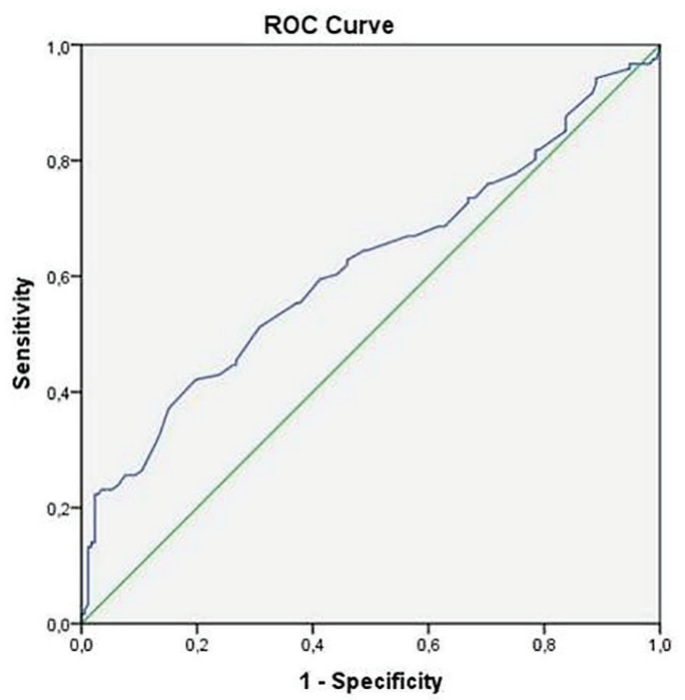


Table 3. All findings and Mortality

\begin{tabular}{|c|c|c|c|}
\hline & Mortality (-) & Mortality (+) & $\mathbf{p}$ \\
\hline Lymphocyte, Median (IQR) & $650(395-1010)$ & $510(310-730)$ & 0.001 \\
\hline CRP, Median (IQR) & 105(37.5-165) & $117(50.2-184)$ & 0.001 \\
\hline Fibrinogen, Median (IQR) & $4.08(2.31-4.85)$ & 7.1(3.68-6.94) & 0.001 \\
\hline D-dimer, Median (IQR) & $1(0.7-1.7)$ & $3.35(1.6-6.6)$ & 0.001 \\
\hline IL-6, Median (IQR) & $40.3(16-87.8)$ & $44(17.7-109.7)$ & 0.581 \\
\hline Troponin T, Median (IQR) & $30(14.7-147)$ & $52(9.6-134)$ & 0.078 \\
\hline Ferritin, Median (IQR) & $507(271-1058)$ & $545(197-1099)$ & 0.206 \\
\hline & $<30 \mathrm{ng} / \mathrm{ml}$ & $\geq 30 \mathrm{ng} / \mathrm{ml}$ & $\mathrm{p}$ \\
\hline Lymphocyte, OR (95\%Cl) & \multicolumn{2}{|c|}{$0.9(0.99-1)$} & 0,025 \\
\hline CRP, OR (95\%CI) & \multicolumn{2}{|c|}{$1(0.99-1)$} & 0.892 \\
\hline Fibrinogen, OR $(95 \% \mathrm{Cl})$ & \multicolumn{2}{|c|}{$2(1.59-2.53)$} & 0.001 \\
\hline D-dimer, OR (95\%Cl) & \multicolumn{2}{|c|}{$2.3(1.71-3.01)$} & 0.001 \\
\hline IL-6, OR (95\%CI) & \multicolumn{2}{|c|}{$1(0.99-1)$} & 0.525 \\
\hline Troponin T, OR $(95 \% \mathrm{Cl})$ & \multicolumn{2}{|c|}{$1(1-1)$} & 0.656 \\
\hline Ferritin, OR $(95 \% \mathrm{Cl})$ & \multicolumn{2}{|c|}{$1(1-1)$} & 0.47 \\
\hline & Mortality (-) & Mortality (+) & $p$ \\
\hline Sex, OR (95\%Cl) & \multicolumn{2}{|c|}{$1.52(0.84-2.73)$} & 0.158 \\
\hline Age, OR $(95 \% \mathrm{Cl})$ & \multicolumn{2}{|c|}{$0.96(0.93-1)$} & 0.068 \\
\hline ARDS, OR (95\%CI) & \multicolumn{2}{|c|}{$0.43(0.23-0.81)$} & 0.01 \\
\hline $\begin{array}{l}\text { Vitamin D, OR }(95 \% \mathrm{Cl}) \\
\text { Sufficent } \\
\text { Insufficient } \\
\text { Deficiency }\end{array}$ & \multicolumn{2}{|c|}{$\begin{array}{c}\text { Reference } \\
2.5(1.06-5.86) \\
3.86(1.72-8.65)\end{array}$} & $\begin{array}{l}0.035 \\
0.001\end{array}$ \\
\hline $\begin{array}{l}\text { Chest Tomography Stage, OR }(95 \% \mathrm{Cl}) \\
\text { Stage } 1 \\
\text { Stage } 2 \\
\text { Stage } 3\end{array}$ & \multicolumn{2}{|c|}{$\begin{array}{c}\text { Reference } \\
0.22(0.11-0.44) \\
2.79(1.39-5.61)\end{array}$} & $\begin{array}{l}0.001 \\
0.001\end{array}$ \\
\hline Diabetes, OR (95\%CI) & \multicolumn{2}{|c|}{$1.56(0.88-2.79)$} & 0.627 \\
\hline Hypertension, OR $(95 \% \mathrm{Cl})$ & \multicolumn{2}{|c|}{$1(0.52-1.98)$} & 0.963 \\
\hline Coronary Artery Disease, OR (95\%Cl) & \multicolumn{2}{|c|}{$0.75(0.4-1.41)$} & 0.38 \\
\hline Chronic Kidney Disease, OR (95\%Cl) & \multicolumn{2}{|c|}{$0.71(0.29-1.69)$} & 0.43 \\
\hline Cerebrovascular Diseases, OR $(95 \% \mathrm{Cl})$ & \multicolumn{2}{|c|}{$0.7(0.25-1.97)$} & 0.508 \\
\hline Asthma, OR (95\%Cl) & \multicolumn{2}{|c|}{$1.79(0.63-5.05)$} & 0.27 \\
\hline Chronic obstructive pulmonary disease, OR 95\%Cl) & \multicolumn{2}{|c|}{$1.44(0.65-3.19)$} & 0.366 \\
\hline
\end{tabular}

IQR: Interquartile Range, OR: Odds Ratio, Cl: Confidence Interval 


\section{DISCUSSION}

\section{Vitamin D and inflammation}

Vitamin $D$ is an immunomodulatory molecule that mitigates strong proinflammatory reactions. It downregulates the Th1-mediated immune response by inhibiting the production of pro-inflammatory cytokines, such as IFN- $\gamma$, IL-6, IL-2, and TNF- $\alpha$. In addition, the immunomodulatory effect of vitamin $D$ is demonstrated by reducing plasma cells and immunoglobulin release, increasing anti-inflammatory cytokine production, activating Toll-like receptors, and increasing the release of antimicrobial peptides, such as cathelicidin and $\beta$-defensin (5). Moreover, it has been reported that vitamin $D$ balances the inflammatory response by increasing the expression of angiotensin-converting enzyme 2, which is an anti-inflammatory component of the angiotensin-converting enzyme 2/angiotensin/Mas receptor axis (6).

Due to its immunomodulatory effect, studies have shown that vitamin $D$ reduces the severity and incidence of bacterial and viral infections. In addition, it has been reported that vitamin D deficiency increases the risk of respiratory infections, such as influenza and respiratory syncytial virus (7). In addition, vitamin $D$ deficiency has been shown to play a role in the development of ARDS (8).

We detected an inverse correlation between the vitamin D and the IL-6, ferritin, fibrinogen, and CRP levels and a positive correlation with lymphocyte count in our study. However, in the regression analysis, vitamin D deficiency, high fibrinogen level, and low lymphocyte count ad the most significant relationship. In particular, vitamin D deficiency increased the risk of high fibrinogen levels by 1.8 times. Previous studies have shown a relationship between lymphocyte count, fibrinogen level, and vitamin D deficiency (9). A similar relationship has been observed in patients with COVID-19 (10). Furthermore, we found a significant correlation between mortality, D-dimer and fibrinogen levels, and lymphocyte count. It is a known fact that the presence of hy- percoagulopathy (especially in severe COVID-19) is present with hypercoagulability and hyperfibrinolysis and affects the prognosis negatively $(11,12)$. Therefore, a number of patients with COVID-19 developed venous and arterial thromboses, which are often associated with high mortality rates $(12,13)$. Hypercoagulability in severe COVID-19 mainly manifests as increased levels of D-dimer and fibrinogen (14). We believe that the improvement of vitamin $D$ deficiency may be important for the prevention of hypercoagulopathy.

\section{Vitamin $D$ and lung outcomes}

Cytokines activated by macrophages, neutrophils, and $\mathrm{T}$ cells cause lung damage by inducing type 2 pneumocyte apoptosis. In some cases, a cytokine storm may result in damage reminiscent of severe viral pneumonia, which can result in bilateral lung injury, hypoxemia, and sometimes ARDS (15). ARDS has been reported as the most common complication in cases of mortality (16). Therefore, vitamin D may be considered a preventive agent and an immunomodulator. Previous studies have shown the negative effect of vitamin $D$ deficiency on viral respiratory infections. However, there have been some varying findings in the association of vitamin $\mathrm{D}$ deficiency and viral respiratory infections due to different methodologies $(17,18)$. A recent systematic review and meta-analysis concluded that vitamin $D$ has the potential to prevent respiratory infections, especially in high-level deficiency (19).

We detected that ARDS and severe pneumonia were more common in the vitamin $D$ deficient group. The length of stay in the ICU was longer in this group. Few studies on COVID-19 have reported a relationship between ARDS and severe pneumonia and vitamin $D$ deficiency in different age and sample groups. These data supporting the positive effect on lung outcomes may support vitamin D supplementation in COVID-19 patients with vitamin $D$ deficiency. However, these issues need to be addressed by randomized controlled trials. 


\section{Vitamin D and confounding factors}

The study group included patients with confounding comorbidities. Chronic lung and kidney diseases are known to alter the $25(\mathrm{OH})$ metabolism $(20,21)$. In addition, vitamin D deficiency correlates with coronary artery disease, arterial hypertension, and diabetes, and all are known risk factors for COVID-19 survival $(22,23)$. In our study, no association was found between comorbidities and mortality. We found a strong relationship between vitamin $D$ deficiency and mortality, with an OR of 2.45 , independent of comorbidities. However, we had no data on the patients' previous vitamin D intake. Nevertheless, these data may indicate that the vitamin $D$ level is a useful marker for inflammation, coagulation, and lung damage in patients with COVID-19.

\section{Vitamin D and mortality}

We determined the relationship between mortality and vitamin D deficiency in each laboratory, comorbidities, and clinical parameters. In the logistic regression analysis, high fibrinogen and D-dimer levels, ARDS, vitamin D deficiency, and severe pneumonia were also risk factors for mortality. Systemic reviews have reported a potential association between vitamin $D$ deficiency and mortality $(24,25)$, and our study showed that patients with vitamin $D$ deficiency and COVID-19 had 3.86 times higher risk of mortality. We found that the cut-off value for mortality in COVID-19 patients is $18.5 \mathrm{ng} / \mathrm{mL}$.

\section{Limitations}

This study had some limitations. The study was conducted retrospectively, and further studies may address some of these limitations. First, we had no information on the following patient characteristics: previous intake of vitamin D supplements, sunlight exposure status, or high rate of vitamin D deficiency in patients with COVID-19 who had an accelerated metabolism of vitamin D in an inflammatory cascade due to infection and hospitalization. Second, all of our patients were severe patients admitted to the tertiary ICU. As such, most of our patients received immunomodulatory therapy, which could have affected the inflammatory pathway. Mechanical ventilator-induced risk factors may also cause mortality or pneumonia. Finally, this study's population only included patients aged $>65$ years. This age group may have different risk factors for mortality and outcomes of COVID-19. Therefore, it can be difficult to associate all results with vitamin $\mathrm{D}$ deficiency.

\section{Conclusions}

In summary, our study showed an association between vitamin $D$ deficiency and admission and mortality, severity of inflammation, and pneumonia, independent of the vitamin D-impacted comorbidities. We believe that the curfew hours of the aged population should be arranged in consideration of these findings since this population has been locked inside for days at home due to the government's pandemic-related rules. We also recommend that this population be provided vitamin D supplements, which are easy to obtain, cheap, and safe.

\section{Conflict of Interest:}

The authors declare that they have no conflicts of interest. The authors have indicated that they have no financial relationships relevant to this article to disclose.

Ethical Approval: All procedures performed in this study involving human participants were in accordance with the ethical standards of the institutional and/or national research committee and with the 1964 Helsinki declaration and its later amendments or comparable ethical standards.

Acknowledgements: None 


\section{REFERENCES}

1. Ali N. Role of vitamin D in preventing of COVID-19 infection, progression and severity. J Infect Public Health 2020; 13(10):1373-80. (PMID: 32605780)

2. Mitchell F. Vitamin-D and COVID-19: do deficient risk a poorer outcome? Lancet Diabetes Endocrinol. 2020;8(7): 570. (PMID: 32445630)

3. Lips P, Cashman KD, Lamberg-Allardt C, et al (2019). Current vitamin D status in European and Middle East countries and strategies to prevent vitamin D deficiency: a position statement of the European Calcified Tissue Society. Eur J Endocrinol 180(4): P23-P54. (PMID: 30721133)

4. Mohan M, Cherian JJ, Sharma A. Exploring links between vitamin D deficiency and COVID-19. PLoS Pathog 2020;16(9):e1008874. (PMID: 32946517)

5. Lemire JM. Immunomodulatory role of 1,25-dihydroxyvitamin D3. J Cell Biochem 1992;49(1):26-31. (PMID: 1644850)

6. Cui $C, X u P, L i G$, et al. Vitamin $D$ receptor activation regulates microglia polarization and oxidative stress in spontaneously hypertensive rats and angiotensin II-exposed microglial cells: Role of renin-angiotensin system. Redox Biol 2019;26:101295. (PMID: 31421410)

7. Zisi D, Challa A, Makis A. The association between vitamin $D$ status and infectious diseases of the respiratory system in infancy and childhood. Hormones (Athens) 2019;18(4):353-63. (PMID: 31768940)

8. Dancer RC, Parekh D, Lax S, et al. Vitamin D deficiency contributes directly to the acute respiratory distress syndrome (ARDS). Thorax 2015; 70(7):61724. (PMID:25903964)

9. Mellenthin L, Wallaschofski H, Grotevendt A, Völzke $H$, Nauck M, Hannemann A. Association between serum vitamin $D$ concentrations and inflammatory markers in the general adult population. Metabolism 2014;63(8):1056-62. (PMID: 24928661)

10. Zheng $M$, Gao Y, Wang G, et al. Functional exhaustion of antiviral lymphocytes in COVID-19 patients. Cell Mol Immunol 2020;17(5):533-5. (PMID: 32203188)

11. Mohammad S, Mishra A, Ashraf MZ. Emerging Role of Vitamin D and its Associated Molecules in Pathways Related to Pathogenesis of Thrombosis. Biomolecules 2019;9(11):649. (PMID: 31653092)

12. Wool GD, Miller JL. The Impact of COVID-19 Dis- ease on Platelets and Coagulation. Pathobiology 2021;88(1):15-27. (PMID: 33049751)

13. Klok FA, Kruip MJHA, van der Meer NJM, et al. Incidence of thrombotic complications in critically ill ICU patients with COVID-19. Thromb Res 2020; 191:1457. (PMID: 32291094)

14. Han $H$, Yang $L$, Liu $R$, et al. Prominent changes in blood coagulation of patients with SARS-CoV-2 infection. Clin Chem Lab Med 2020; 58(7):1116-20. (PMID:32172226)

15. McGonagle D, Sharif K, O'Regan A, Bridgewood C. The Role of Cytokines including Interleukin-6 in COVID-19 induced Pneumonia and Macrophage Activation Syndrome-Like Disease. Autoimmun Rev 2020; 19(6):102537. (PMID: 32251717)

16. Qiu P, Zhou Y, Wang F, et al. Clinical characteristics, laboratory outcome characteristics, comorbidities, and complications of related COVID-19 deceased: a systematic review and meta-analysis. Aging Clin Exp Res 2020; 32(9):1869-78. (PMID: 32734576)

17. Zittermann A, Pilz S, Hoffmann H, März W. Vitamin D and airway infections: a European perspective. Eur J Med Res 2016; 21:14. (PMID: 27009076)

18. Robertsen S, Grimnes G, Melbye H. Association between serum 25-hydroxyvitamin $D$ concentration and symptoms of respiratory tract infection in a Norwegian population: the Tromsø Study. Public Health Nutr 2014;17(4):780-6. (PMID:23659381)

19. Martineau AR, Jolliffe DA, Hooper RL, et al. Vitamin $D$ supplementation to prevent acute respiratory tract infections: systematic review and meta-analysis of individual participant data. BMJ 2017;356:i6583. (PMID: 28202713)

20. Bellasi A, Galassi A, Mangano M, Di Lullo L, Cozzolino M. Vitamin D Metabolism and Potential Effects of Vitamin D Receptor Modulation in Chronic Kidney Disease. Curr Drug Metab 2017; 18(7):680-8. (PMID: 28460623)

21. Hiemstra PS, de Jongh RT. Vitamin D Deficiency in Asthma and Chronic Obstructive Pulmonary Disease. A Chicken-or-Egg Story. Am J Respir Crit Care Med. 2020;202(3):312-3. (PMID: 32352312)

22. Williamson EJ, Walker AJ, Bhaskaran K, et al. Factors associated with COVID-19-related death using OpenSAFELY. Nature 2020;584(7821):430-6. (PMID:32640463) 
23. Bello-Chavolla OY, Bahena-López JP, Antonio-Villa NE, et al. Predicting Mortality Due to SARS-CoV-2: A Mechanistic Score Relating Obesity and Diabetes to COVID-19 Outcomes in Mexico. J Clin Endocrinol Metab 2020;105(8):dgaa346. (PMID:32474598)

24. Oscanoa TJ, Amado J, Vidal X, Laird E, Ghashut RA, Romero-Ortuno R. The relationship between the severity and mortality of SARS-CoV-2 infection and 25-hydroxyvitamin D concentration - a metaanalysis. Adv Respir Med 2021; 89(2):145-57. (PMID: 33966262)

25. Dra mé $M$, Cofais $C$, Hentzien $M$, et al. Relation between Vitamin D and COVID-19 in Aged People: A Systematic Review. Nutrients 2021;13(4):1339. (PMID:33920639) 